\title{
Medievalista
}

Online

$24 \mid 2018$

Número 24

\section{El aprovechamiento del cauce fluvial en una encomienda andaluza de la Orden de San Juan: las aceñas de Alcolea del Río en el siglo XV}

The use of the river in an Andalusian territory governed by the Order of Saint John: water mills in Alcolea del Río during the 15th century

\section{Juan Carlos Arboleda Goldaracena}

\section{OpenEdition}

\section{Journals}

\section{Edição electrónica}

URL: http://journals.openedition.org/medievalista/1704

DOI: $10.4000 /$ medievalista. 1704

ISSN: 1646-740X

\section{Editora}

Instituto de Estudos Medievais - FCSH-UNL

\section{Refêrencia eletrónica}

Juan Carlos Arboleda Goldaracena, «El aprovechamiento del cauce fluvial en una encomienda andaluza de la Orden de San Juan: las aceñas de Alcolea del Río en el siglo XV », Medievalista [Online], 24 | 2018, posto online no dia 14 março 2019, consultado no dia 04 maio 2019. URL : http:// journals.openedition.org/medievalista/1704; DOI : 10.4000/medievalista.1704

Este documento foi criado de forma automática no dia 4 Maio 2019

(C) IEM 


\section{El aprovechamiento del cauce fluvial en una encomienda andaluza de la Orden de San Juan: las aceñas de Alcolea del Río en el siglo XV}

The use of the river in an Andalusian territory governed by the Order of Saint John: water mills in Alcolea del Río during the 15th century

Juan Carlos Arboleda Goldaracena

\section{NOTA DO EDITOR}

Data recepção do artigo / Received for publication: 03-01-2018

Data aceitação do artigo / Accepted in revised form: 15-06-2018

\section{Introducción}

1 En palabras de Fernando Luis Corral, "los molinos o las aceñas suponen para el estudioso de la Edad Media uno de los elementos más interesantes a la hora de profundizar en la investigación histórica [...]. No deja de sorprender con qué maestría nuestros antepasados

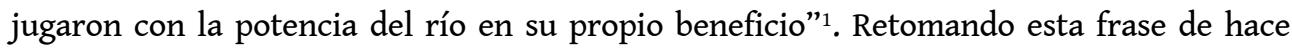
más de dos décadas que servía como inicio a un estudio sobre las aceñas zamoranas en la Plena Edad Media, queremos en este trabajo poner en evidencia su papel dentro de la trama económica y social de un marco geográfico preciso, la vega media del Guadalquivir, y en concreto de un territorio dependiente de la Orden de San Juan que durante el siglo $\mathrm{XV}$ fue consolidando su poder político y económico hasta convertirse en una entidad autónoma dentro de las posesiones de la Orden: la encomienda de Alcolea del Río, en la actual provincia de Sevilla, a 53 kilómetros de la capital. 
2 Aunque son pocos los datos referentes a Alcolea en la Edad Media, siendo muchísimo más abundante la información sobre esta encomienda durante la Edad Moderna, y esto es extensible a las propias aceñas alcoleanas, la documentación conservada - parte de ella ya editada aunque no del todo explotada y otra parte aún inédita - nos permite hacer una reconstrucción bastante precisa del panorama relativo al siglo XV, que es el período del que datan la mayor parte de los documentos. Con ellos trataremos de describir los distintos grupos de aceñas existentes en Alcolea a fines de la Edad Media, ubicándolas espacialmente y analizando las condiciones de su explotación y los distintos pleitos derivados de su uso, para constatar que el aprovechamiento del río supuso una fuente de riqueza importante dentro del sistema económico de la encomienda, que como ya hemos dicho sufrió un acusado desarrollo durante el siglo XV.

\section{Las aceñas bajomedievales del Guadalquivir y su entorno}

3 El uso de los cauces fluviales para el desarrollo de obras de ingeniería que permitiesen el aprovechamiento del agua para diversos fines ya era conocido en la Península Ibérica durante las dominaciones romana y árabe ${ }^{2}$. Una de estas construcciones fueron las aceñas ${ }^{3}$, molinos hidráulicos que aprovechaban la fuerza del río para moler el cereal, o los batanes, que hacían lo propio para compactar tejidos. Técnicamente, reciben el nombre de aceñas aquellas construcciones que poseen una rueda vertical y se usan en ríos con mayor caudal, frente a los llamados simplemente molinos, que usan una rueda horizontal y se aprovechan mejor en cauces menos abundantes ${ }^{4}$. Las aceñas disponían de un azud o azuda, que era una especie de presa situada perpendicularmente a la corriente y que desviaba el agua del cauce principal del río hacia la 'bullonera', un embalse que la dirigía directamente a las ruedas del molino mediante acequias o canales. Esta parte también recibía el nombre de 'pesquera' o 'pesquería' por su aprovechamiento para la obtención de los peces arrastrados por la corriente hacia ese embalse que formaba la presa ${ }^{5}$. Los detalles técnicos del interior de los molinos, sus utensilios y la tecnología empleada en ellos han sido estudiados minuciosamente por el profesor Córdoba de la Llave ${ }^{6}$.

4 En el caso andaluz, la cuenca del Guadalquivir con sus afluentes cobró un protagonismo importante en el uso de molinos hidráulicos durante la Edad Media, sin duda como herencia recibida de la presencia musulmana en la Península. Y esto se explica por dos motivos: la propia importancia y fuerza del caudal del río, que lo convierte en un recurso imprescindible; y su paso por zonas destinadas a la producción de cereal, como la Campiña sevillana, sobre todo para el caso de las aceñas o molinos harineros, que son los que nos ocupan. A lo largo de las provincias de Jaén, Córdoba ${ }^{7}$ y Sevilla, la presencia de aceñas y molinos en el curso del río es constante y documentada al menos desde los últimos siglos medievales.

5 Centrándonos en la actual provincia de Sevilla, ya desde la Reconquista la mayoría de los molinos harineros se ubicaban en la Campiña, y más concretamente en el río Guadaíra ${ }^{8}$ y en la zona de Carmona, cuyo término limita con el de Alcolea, ya que esta era la comarca más importante del reino de Sevilla en lo que a producción de cereal se refiere`. Aun así, también había molinos en otras zonas como el Aljarafe, en torno al río Guadiamar o en la Sierra Norte ${ }^{10}$. Muchos de estos molinos pertenecieron al cabildo catedralicio de Sevilla ${ }^{11}$ 
o a órdenes militares, como la que nos ocupa, que poseía construcciones de este tipo en el río Guadaíra ${ }^{12}$ y en Carmona ${ }^{13}$, fuera de los límites de sus encomiendas ${ }^{14}$.

6 Aunque se sabe que el sur peninsular no se caracterizó por la abundancia en la producción cerealista ${ }^{15}$, la presencia de molinos harineros sí era necesaria al menos en las zonas destinadas a ello. El cultivo de cereales (fundamentalmente trigo y cebada, y esta última en dos variedades: una para el consumo humano y otra para la alimentación del ganado) se hacía siguiendo el sistema de alternancia, por el que la parcela en la que se ha sembrado un año se deja descansar en barbecho al año siguiente, con el propósito de evitar el agotamiento de la tierra. Esta rotación podía hacerse dividiendo la parcela en dos partes o bien sembrando toda la parcela cada dos años. También se utilizó en estas tierras el antiguo sistema de 'rozas', consistente en limpiar las tierras incultas prendiéndoles fuego, constituyendo a veces verdaderas roturaciones ${ }^{16}$. La producción de cereales necesitaba de una inversión previa para la compra de semillas, por lo que resultaba bastante costosa. Es por ello que en este tipo de tierras predominó la asociación entre campesinos para hacer frente a la explotación ${ }^{17}$ o bien la posesión de los terrenos por parte de personalidades destacadas del reino de Sevilla, como sucedía en la vega de Carmona, en las proximidades de Alcolea, donde condes como el de Niebla, o miembros de la baja nobleza sevillana, o el propio cabildo catedralicio ostentaban la propiedad de distintas tierras destinadas al cultivo de cereal ${ }^{18}$.

\section{La encomienda sanjuanista de Alcolea en la Edad Media}

7 La Orden de San Juan ${ }^{19}$ llegó a Andalucía con las tropas del rey Fernando III y recibió del monarca distintas posesiones a lo largo del río Guadalquivir, conformando un importante señorío cuya cabeza inicial era la encomienda de Setefilla (pasando posteriormente a Lora del Río, y convirtiéndose en el siglo XVI en bailía), de la que dependían además los territorios de Tocina, Robayna (en el Aljarafe sevillano) y Alcolea. Este amplio dominio estaba integrado dentro del Priorato de la Orden en Castilla y León, que pertenecía a la Lengua de Castilla y Portugal ${ }^{20}$. En concreto, Alcolea ${ }^{21}$ fue arrebatada a los musulmanes en torno a 1247 y entregada a la Orden de San Juan por Fernando III en $1249^{22}$. Se ubica en la confluencia del río Corbones y el Guadalquivir y su nombre deriva del árabe Al-Qulay'a o Al-Koliah, que significa "pequeña fortaleza”, en una zona donde hay restos de dos ciudades romanas, Arva y Canama (esta última muy próxima al actual núcleo urbano), además de distintos poblamientos de otras épocas ${ }^{23}$.

8 Tras su incorporación a los territorios de la Orden, Alcolea se convierte en una aldea dependiente de la encomienda de Setefilla y Lora, con un pequeño concejo rural compuesto por dos alcaldes y un alguacil - propuestos por los vecinos y nombrados por el comendador loreño - y un prior parroquial que atendía el servicio de la iglesia de San Juan Bautista ${ }^{24}$, edificada probablemente durante el siglo XIV en estilo mudéjar, siguiendo el tipo parroquial sevillano. Salvo para los casos de justicia menor, la jurisdicción sobre Alcolea se ejercía directamente desde la encomienda de Setefilla, con su comendador o teniente a la cabeza. La jurisdicción eclesiástica era administrada por la Orden, al tratarse de un territorio vere nullius dioecesis, ejerciendo el prior parroquial de Lora como vicario de todo el territorio, con funciones quasiepiscopales, aunque con el tiempo cada una de 
las encomiendas tendrá su propio vicario, en la figura de los distintos priores parroquiales locales.

9 En el término de Alcolea había tres tipos de tierras: las del concejo, las de la encomienda y las de repartimiento, que el comendador debía repartir entre los vecinos con carácter vitalicio. Los cultivos predominantes, por la proximidad con la Campiña, eran el trigo y la cebada, por lo que la existencia de aceñas o molinos harineros queda plenamente justificada dentro del territorio de la encomienda. Precisamente, y en relación con la producción de cereal, Alcolea fue protagonista a finales de la Edad Media, junto con el resto de territorios del señorío sanjuanista andaluz, de un sonado pleito contra el cabildo catedralicio de Sevilla a tenor del cobro del tercio de los diezmos del pan, que los capitulares pretendían cobrar aunque la Orden alegaba que estaba exenta del pago por bula papal. El conflicto duró hasta el siglo XIX.

10 Alcolea supo aprovechar la presencia del río como un motor importante de su economía. Así, además de las aceñas, que estudiamos detenidamente en el siguiente apartado, contaba también en su término con una barca para cruzar el Guadalquivir, que le generaba importantes rentas y que fue origen a finales del siglo XIV de otro pleito con el concejo de Sevilla, que poseía también barcas en otros puntos del río. El conflicto se solventó con el compromiso de la Orden de eliminar la barca de Alcolea, recibiendo a cambio la tercera parte de las rentas de otra barca que unía Villanueva con Tocina, propiedad del concejo, a la que posteriormente se le añadieron dos más, en los términos de Tocina y El Pedroso ${ }^{25}$.

11 Aunque para el período medieval no disponemos de datos demográficos, sabemos que a comienzos del siglo XVI Alcolea contaba con 140-300 vecinos (unos 1000 habitantes) ${ }^{26}$. Lo que sí es evidente es el hecho de que durante el siglo XV, ya superada la crisis demográfica del XIV, Alcolea creció en población y término, a la par que lo hacía también su economía, llegando a establecer de facto una encomienda independiente con comendadores documentados desde la primera mitad del siglo, que ejercían el control del territorio no sin los lógicos problemas con Lora, que no quería aceptar dicha independencia. La segregación definitiva se produce el 17 de diciembre de 1504, en Capítulo General de la Lengua de Castilla y Portugal celebrado en Rodas, creándose oficialmente la encomienda de Alcolea (que ya lo era a efectos prácticos desde casi un siglo antes), y perdurando como tal hasta el siglo XIX.

\section{Las aceñas de Alcolea en el siglo XV}

\subsection{Identificación y características}

Durante el período bajomedieval hubo en Alcolea al menos tres grupos ${ }^{27}$ de aceñas diferentes, ubicadas en distintos puntos del término de la encomienda. Analizamos en este apartado cada uno de estos tres grupos y los datos conocidos hasta el momento sobre sus características y ubicación:

13 i) La primera aceña o grupo de aceñas de que tenemos constancia es la llamada aceña de Don Lope o del Conde, ubicada entre el núcleo urbano de Alcolea y el de Villanueva del Camino (hoy Villanueva del Río). Sabemos que estas aceñas fueron construidas en el siglo XIV por Bartolomé Martínez de Medina ${ }^{28}$, alcaide de las atarazanas de Sevilla durante el reinado de Pedro ${ }^{29}$. En 1405, la propiedad de las aceñas estaba en manos de Gonzalo 
Sánchez de Andújar, canónigo de la catedral de Sevilla, que poseía una tercera parte de las mismas; y el resto era de los hijos de Constanza Fernández de Frías, viuda de Alvar Rodríguez de Esquivel, vecinos de Sevilla ${ }^{30}$. En 1454 eran propiedad de Lope de León, Mayor de Esquivel y Juan de Esquivel (uno de los hijos del matrimonio mencionado anteriormente), quienes las tenían arrendadas a Gabriel de Montoro ${ }^{31}$. González Carballo ${ }^{32}$ y Trujillo ${ }^{33}$ indican que en el siglo XVI esta aceña era propiedad del duque de Arcos, sin que hasta la fecha se hubiera podido identificar en qué momento pasa a manos de esta casa nobiliaria. Pues bien, la consulta de los fondos del Archivo Histórico de la Nobleza nos ha permitido localizar un documento de venta de parte de estas aceñas en el año 1483, en el que Pedro Ponce de León, hijo de don Lope de León (anteriormente mencionado), vende a su primo Rodrigo Ponce de León, último marqués y primer duque de Cádiz, la cuarta parte de las aceñas con su pesquería, cañamales, dehesas y sotos, por 574.000 maravedíes $^{34}$. Se trata del abuelo de Rodrigo Ponce de León y Ponce de León, primer duque de Arcos. Según Trujillo, estas aceñas desaparecen en torno al año $1660^{35}$.

ii) Un segundo grupo de aceñas son las llamadas aceñas de Saldaña, existentes aún en la actualidad - aunque en desuso - y que constituyen uno de los atractivos del patrimonio de Alcolea, ya que se ubican a escasos metros del núcleo urbano. De estas aceñas las primeras noticias que tenemos se remontan a los inicios del siglo XVI. En concreto, sabemos que en 1501 eran propiedad del concejo de Carmona, quien autoriza la construcción de un azud y pesquerías a la persona arrendataria, que en ese momento era Cristóbal Díaz de Cantillana, vecino de Sevilla en la collación de San Lorenzo. A cambio, este debería pagar un tributo de mil trescientos maravedíes al año y dejar moler en ella a los vecinos de Carmona, al precio de un almud de cada doce almudes (una fanega) de trigo ${ }^{36}$. No obstante, el estudio de las características arquitectónicas ${ }^{37}$ de este grupo de aceñas ${ }^{38}$ permite datarlas como una construcción bajomedieval, posiblemente algo posteriores al primer grupo de aceñas ya mencionadas, aunque sin descartar el aprovechamiento de alguna construcción primitiva romana o musulmana. En palabras de Gómez de Terreros:

"Los tres molinos presentan interesantes singularidades constructivas: están dispuestos en forma de tajamares muy agudos en sentido de la corriente, son de planta poligonal, y sus zonas bajas son de sillería y el resto de ladrillo. El primer molino posee una estructura similar a la quilla de una nave invertida y aparece flanqueado por dos grandes contrafuertes. El central es de planta pentagonal y se cubre con una bóveda de medio cañón dividida en tres tramos desiguales, separados mediante pilastras realizadas en cantería y ladrillo. La tercera construcción tiene planta pentagonal y cubierta con bóveda estrellada formada por cruce de vigas, que da lugar a una original solución arquitectónica. Hacia el sur, el conjunto de edificaciones acaba con un espigón que se adentra en el río, realizado a base de sillares y guijarros que interiormente estaban enlucidos con un material semejante al estuco. Inicialmente tenían seis piedras de moler, pero a principios del siglo XX solo funcionaban cuatro" ${ }^{39}$.

iii) Por último, encontramos las llamadas aceñas de la Peña de la Sal, en el límite de los términos de Alcolea y Lora del Río. Deben ser posteriores, de finales del siglo XV o principios del XVI. Sancho Corbacho fecha su construcción en el Renacimiento ${ }^{40}$. Se ubican en una zona con numerosos restos arqueológicos, pues en sus inmediaciones se localizaba la ciudad romana de $\operatorname{Arva}^{41} \mathrm{y}$ otro yacimiento distinto, con una necrópolis cristiana, que recibe también el nombre de Peña de la Sal ${ }^{42}$. Nada dicen de ellas los documentos con respecto al siglo XV. Durante el XVI sabemos que estaban en manos del mariscal Diego Caballero en 1553 y del conde de Olivares en $1593^{43}$. 


\subsection{Condiciones de explotación}

16 Como es lógico, el señorío jurisdiccional y territorial ejercido por los sanjuanistas en sus posesiones les aseguraba el derecho a la percepción de diferentes tributos y rentas procedentes de muy diversas actividades, entre las que se incluían el arrendamiento de bienes de la Orden (tierras, casas, tiendas, molinos...), el establecimiento de monopolios, los impuestos sobre determinados productos o sobre el comercio y tránsito de mercancías o las tasas por la administración de justicia ${ }^{44}$. Entre estas rentas estaban las procedentes de la explotación de las aceñas, al estar en territorios donde la Orden ejercía su señorío.

Como indica Fernando Luis Corral ${ }^{45}$, para el caso de las aceñas raramente los documentos bajomedievales nos hablan de rentas o beneficios de las mismas - que debían ser importantes a tenor del interés de personajes poderosos por hacerse con su control -, y estos empiezan a hacerse visibles en la documentación a partir del siglo XV. Es lo que sucede con el caso de Alcolea, para el que contamos únicamente con un contrato de explotación fechado a principios de esta centuria, y que nos va a servir como modelo para el estudio de la realidad de la zona ${ }^{46}$. Se trata de un contrato referido a la aceña de Don Lope o del Conde, la más antigua de las existentes en Alcolea, como ya hemos visto.

El documento incluye la transcripción de otro fechado unos días antes, el 27 de julio, mediante el cual se nombra procurador en este asunto a Fernando Alonso, vecino de Villanueva del Camino, para que actúe en nombre de una de las partes interesadas, en concreto cuatro de los hijos del matrimonio propietario, al ser menores. Como ya vimos en el apartado anterior, en este momento la aceña estaba en manos de Gonzalo Sánchez de Andújar, canónigo de la catedral de Sevilla, que poseía una tercera parte de la misma; y el resto era de los hijos de Constanza Fernández de Frías, viuda de Alvar Rodríguez de Esquivel, vecinos de Sevilla. De estos hijos, llamados Juan Álvarez, Juan de Esquivel, Diego Sánchez, Juana Sánchez y Constanza, los cuatro últimos aún eran menores de edad. La propiedad compartida de las aceñas era algo bastante frecuente, y muchas veces su uso estaba regulado por horas ${ }^{47}$.

El contrato refiere que la construcción se debió al ya mencionado Bartolomé Martínez de Medina en el siglo anterior, y que fue este quien acordó con la Orden que las aceñas rentarían perpetuamente a favor de los hospitalarios diez cahíces de trigo al año, la cuarta parte de los peces ${ }^{48}$ que entrasen en su canal y la posibilidad de hacer uso de la barca o barquete que había en las mismas ${ }^{49}$. De esta manera, los nuevos propietarios se comprometen con la Orden - en la figura de su prior en Castilla y León, fray Rodrigo Gómez de Cervantes - a cumplir estas condiciones. La cantidad estipulada de trigo la pagarían trimestralmente, los peces cada vez que se realizaran labores de pesca en la aceña, y el uso de la barca por parte del prior o su mayordomo podría hacerse en cada ocasión que estos la necesitaran para ir a la aceña a cobrar este censo. A cambio, el prior autoriza a los propietarios a entrar en las tierras de la Orden para cortar madera o proveerse de ramas y piedras para las aceñas. Las partes se obligan a cumplir el contrato: si los propietarios no cumplen, incurrirán en multa de diez maravedíes por día mientras dure el incumplimiento. Por su parte, Gonzalo Sánchez se compromete a responder con su patrimonio. La Orden también se obliga bajo pago de cinco mil maravedíes, respondiendo igualmente con sus bienes.

20 En el contrato se estipula la renuncia de los propietarios de las aceñas a ciertos derechos que les correspondían en función del marco jurídico vigente, como la facultad de recurrir 
cualquier sentencia elevada contra ellos por causa de las aceñas, el beneficio de velliano, o el beneficio de duobus rei debendi. Renuncian finalmente a cualquier derecho escrito o no escrito, así como a la ley de renunciación general non vala.

La renuncia a estos derechos, frecuente en este tipo de documentos en la época estudiada, es en palabras de Pérez-Prendes "una declaración unilateral, habitualmente reforzada con juramento de observarla, por la que un sujeto del Derecho, que concierta una relación jurídica con otro $u$ otros, transige en no acudir a determinados derechos subjetivos que el ordenamiento le concede, o podría concederle, en orden a la relación que desea dejar jurídicamente constituida"50. Esto, no obstante, planteaba ciertos problemas, ya que el declarante se situaba con su declaración fuera del marco jurídico en el que se ubicaba ${ }^{51}$. Las renuncias se hacían con el propósito de colocar a una de las partes en una posición favorable con respecto al Derecho ${ }^{52}$, en este caso a la Orden como beneficiaria de las rentas de las aceñas al estar estas ubicadas dentro de su señorío.

La omisión del beneficio de velliano - referido al llamado senadoconsulto Veleyano en el Derecho Romano - implicaba la renuncia de la mujer a poder actuar como garante en las obligaciones de pago $^{53}$. El desistimiento de la cláusula de duobus rei debendi era la renuncia al beneficio de división, por lo que se facultaba a la otra parte a actuar contra cualquiera de los deudores por el todo de la deuda u obligación ${ }^{54}$. Por último, la renuncia a la ley de renunciación general non vala suponía el desprecio de la normativa que impedía realizar todas las renunciaciones antes mencionadas ${ }^{55}$.

\subsection{Pleitos derivados del uso de las aceñas}

El uso y explotación de las aceñas fue origen de distintos pleitos entre la Orden y sus propietarios. Sabemos de la existencia, ya entrado el siglo XVI, de diversas ejecutorias a favor de la encomienda frente a las reticencias de algunos propietarios a la hora de abonar las cantidades estipuladas ${ }^{56}$. Pero estas contiendas podían derivarse también del incumplimiento de algunas condiciones establecidas en los contratos de explotación. Es el caso protagonizado por las aceñas de Don Lope en 1454 y en concreto por la persona que en ese momento las tenía arrendadas de sus propietarios, Gabriel de Montoro. Sabemos por un documento ${ }^{57}$ fechado en agosto de ese año que el citado arrendatario acudió al concejo de Alcolea a reclamar la devolución de una acémila cargada de estacas, que él mismo había recolectado en el Soto de la Torrecilla, en término de la encomienda, para reparar el azud de las aceñas. Por orden del mayordomo del concejo, Juan Rodríguez de la Barrera, el alguacil, Alfonso Fernández de Barrios, y varios vecinos de Alcolea - Pedro Martín del Caño, Juan Palomo, Alfonso de Villarreal, Juan del Río y Diego de Medina el mozo - le habían arrebatado el animal y las estacas, alegando que Montoro las había tomado de unas tierras propiedad de la encomienda.

Unos días más tarde, el arrendatario acude a Sevilla, al monasterio de Santiago de la Espada $^{58}$, y presenta reclamación ante el prior del mismo, Alfonso Pérez de Pineda, que era además juez y subconservador del prior de la Orden de San Juan en Castilla y León, estando presentes también fray Juan Ramírez (prior del convento de San Juan de Acre de Sevilla ${ }^{59}$ ) y Pedro Fernández de Salcedo, procuradores del citado prior sanjuanista en Castilla y León, que en ese momento era fray Gonzalo de Quiroga. Gabriel de Montoro entregó copia del contrato de explotación firmado en 1405, estudiado por nosotros en el apartado anterior, para acreditar su derecho a acceder al término de la encomienda con el fin de proveerse de madera para reparar las aceñas. El prior de San Juan de Acre se 
compromete a escribir al comendador y al concejo de Alcolea para ordenar que se cumplan los términos del contrato de explotación. A su vez, Gabriel de Montoro pide una carta de excomunión para los citados miembros del concejo y la orden de devolución de todo lo arrebatado, aceptando el juez su petición, sin que sepamos si finalmente se cumpliría o no el mandato de excomunión.

Nuestra investigación sobre las aceñas alcoleanas nos ha proporcionado también el hallazgo de otros documentos relativos a pleitos, que aunque se refieren al siglo XVII no nos resistimos a reseñar brevemente en este trabajo. Nos referimos a la contienda acaecida en 1623 entre los propietarios de la aceña de Saldaña y el duque de Arcos, que lo era de la aceña del Conde, situada algo más abajo en el curso del río, como ya hemos visto. Ante las quejas del duque, el gobernador de Alcolea ordena destruir una presa que habían hecho los molineros de las aceñas de Saldaña porque esta dejaba sin agua a la aceña del primero $^{60}$. Hemos hallado también una ejecutoria de la Chancillería de Granada ordenando los mismos términos en favor del duque ${ }^{61}$. Como sucedía en otras partes de la Península, en este tipo de pleitos por el caudal del río ganaba siempre el más poderoso ${ }^{62}$.

\section{Conclusiones}

Alcolea del Río consiguió a principios del siglo XVI constituirse por derecho en una encomienda autónoma dentro de los territorios sanjuanistas de la Península. Si esto fue posible se debió sin duda al importante crecimiento económico y demográfico experimentado por la población a lo largo del siglo $\mathrm{XV}$, cuando ya funcionaba de facto como encomienda independiente de la de Lora del Río, no sin los evidentes conflictos con el concejo loreño, que no estaba dispuesto a aceptar esta segregación.

Dentro del crecimiento económico experimentado por Alcolea durante la Baja Edad Media, ocuparon un papel fundamental las labores de aprovechamiento del río Guadalquivir, que baña todo su término, como un importante recurso y como una fuente de riqueza que los alcoleanos supieron usar de manera muy eficiente. En concreto, la presencia de hasta tres grupos diferentes de aceñas da muestra de este aprovechamiento, en unas tierras que además destacan por la presencia mayoritaria en ellas de zonas dedicadas al cultivo de cereal.

El interés de los grupos poderosos por la posesión de las aceñas fue notable, con ejemplos como la casa ducal de Arcos o miembros del cabildo catedralicio de Sevilla, puesto que los beneficios de su explotación debieron ser copiosos. La Orden era consciente de ello y permitió por tanto la relativamente abundante presencia de estos molinos en sus términos, dado que además ella misma recibía indirectamente los beneficios de la explotación de las aceñas al ejercer los derechos inherentes al señorío que ostentaba sobre el territorio de Alcolea.

En definitiva, las aceñas alcoleanas, que hoy constituyen un referente importante dentro del patrimonio de este municipio de la provincia de Sevilla, deben ponerse de relieve, remarcando su valor no únicamente como legado arquitectónico sino como el símbolo de un desarrollo económico que en siglos pasados hizo que la población pudiera erigirse en organismo autónomo, y esto a su vez como herencia y reflejo de lo que desde siempre había sucedido en esta rica zona de la vega del Guadalquivir donde destacó también la presencia de dos importantes ciudades romanas, Arva y Canama. 


\section{BIBLIOGRAFIA}

Fontes manuscritas

Archivo Histórico de la Nobleza (AHN), Osuna, c. 137, docs. 62, 63, 84 y 85.

Fontes impressas

Libro de privilegios de la Orden de San Juan de Jerusalén en Castilla y León (siglos XII-XV) - Museum and Library of the Order of Saint John (MLOSJ), ms. H211. Ed. Carlos de Ayala Martínez et al. Madrid: Editorial Complutense, 1995.

Estudos

ALBERRO SÁNCHEZ, Rafael - "Las aceñas de Alcolea del Río”. Aparejadores: boletín del Colegio Oficial de Aparejadores y Arquitectos Técnicos de Sevilla 49 (1997), pp. 88-95.

ANGULO ÍÑIGUEZ, Diego - Arquitectura mudéjar sevillana de los siglos XIII, XIV y XV. Sevilla: Universidad de Sevilla, 1932.

AYALA MARTíNEZ, Carlos de - “Orígenes de la Orden del Hospital en Castilla y León (1113-1157)”. Hispania Sacra 43 (1991), pp. 775-798.

AYALA MARTÍNEZ, Carlos de - "Orígenes e implantación de la Orden de Jerusalén en la Península Ibérica (siglo XII)". in IZQUIERDO BENITO, Ricardo et al. (Coords.) - La Orden Militar de San Juan en la Península Ibérica durante la Edad Media. Alcázar de San Juan: Patronato Municipal de Cultura de Alcázar de San Juan, 2002, pp. 23-41.

BARQUERO GOÑI, Carlos - Los Hospitalarios en Castilla y León (siglos XII y XIII): señoríos de la Orden de San Juan. Madrid: Universidad Autónoma de Madrid, 1995.

BARQUERO GOÑI, Carlos - "La Orden de San Juan en Castilla y León durante la Edad Media (siglos XII-XV)”. in IZQUIERDO BENITO, Ricardo et al. (Coords.) - La Orden Militar de San Juan en la Península Ibérica durante la Edad Media. Alcázar de San Juan: Patronato Municipal de Cultura de Alcázar de San Juan, 2002, pp. 97-120.

BORRERO FERNÁNDEZ, Mercedes - El mundo rural sevillano en el siglo XV: Aljarafe y Ribera. Sevilla: Diputación de Sevilla, 1983.

BORRERO FERNÁNDEZ, Mercedes - "Cambios políticos y paisaje agrario en la Edad Media. El ejemplo del campo andaluz (s. XIII-XV)”. Cuadernos del CEMYR 7 (1999), pp. 69-94.

CARO BAROJA, Julio - Norias, azudas, aceñas. Madrid: CSIC, 1954.

CARO QUESADA, M Josefa Salud - “Alcolea del Río”. in MORALES PADRÓN, Francisco (Coord.) Catálogo de los archivos parroquiales de la provincia de Sevilla. Sevilla: Banco Español de Crédito, 1992, tomo I, pp. 41-45.

CÓRDOBA DE LA LLAVE, Ricardo - “Aceñas, tahonas y almazaras: técnicas industriales y procesos productivos del sector agroalimentario en la Córdoba del siglo XV". Hispania 48 (170) (1988), pp. 827-874.

CÓRDOBA DE LA LLAVE, Ricardo - "Los molinos hidráulicos de la cuenca del Guadalquivir a fines de la Edad Media: instrumental y equipamiento técnico". Anuario de Estudios Medievales 33 (1) (2003), pp. 291-337. 
CÓRDOBA DE LA LLAVE, Ricardo - Puertos, azudes y norias. El patrimonio hidráulico histórico de Palma del Río (Córdoba). Sevilla: Fundación El Monte, 2004.

CÓRDOBA DE LA LLAVE, Ricardo - "El molino de Martos (Córdoba): de la aceña medieval a la adopción del sistema de regolfo (siglos XV-XVI)". in Actas del IV Congreso Internacional de Molinología. Mallorca: Consejo Insular de Mallorca, 2005, vol. I, pp. 207-228.

CÓRDOBA DE LA LLAVE, Ricardo - Los molinos hidráulicos del Guadalquivir en la ciudad de Córdoba. Estudio histórico y arquitectónico. Madrid: Ministerio de Fomento, 2008.

CÓRDOBA DE LA LLAVE, Ricardo - "El proceso de difusión del molino de regolfo y la sustitución de aceñas de origen medieval en la provincia de Córdoba". Arte, arqueología e historia 17 (2010), pp. 249-264.

GÓMEZ DE TERREROS GUARDIOLA, Ma Gracia - "La arquitectura de la Orden de San Juan de Jerusalén en la provincia de Sevilla". in GÓMEZ DE TERREROS GUARDIOLA, Ma Valle (coord.) - La arquitectura de las órdenes militares en Andalucía: conservación y restauración. Huelva: Universidad de Huelva, 2011, pp. 87-122.

GONZÁLEZ CARBALLO, José - La Orden de San Juan en Andalucía (siglos XIII-XVI). Las Encomiendas. Sevilla: Fundación El Monte, 2002.

GONZÁLEZ CARBALLO, José - "La Orden de San Juan en Sevilla (siglos XIII-XVI)". Historia. Instituciones. Documentos 29 (2002), pp. 163-186.

GONZÁLEZ CARBALLO, José - "La división de la cámara prioral de Lora y su separación del Priorato: la creación de la encomienda de Alcolea y el bailiaje de Lora". Archivo Hispalense 261-266 (2003-2004), pp. 155-166.

GONZÁLEZ CARBALLO, José - Formación y consolidación del señorío de la Orden de San Juan en Andalucía: siglos XIII-XVI. Sevilla: Diputación de Sevilla, 2004.

GONZÁLEZ JIMÉNEZ, Manuel - El concejo de Carmona a fines de la Edad Media (1464-1523). Sevilla: Diputación de Sevilla, 1973.

GONZÁLEZ JIMÉNEZ, Manuel - Catálogo de documentación medieval del Archivo Municipal de Carmona, vol. I (1249-1474). Sevilla: Diputación de Sevilla, 1976.

GONZÁLEZ TASCÓN, Ignacio - “La difusión medieval del molino hidráulico”. in GRAU FERNÁNDEZ, Marta (Coord.) - Ars mechanicae: ingeniería medieval en España. Madrid: Ministerio de Fomento, 2008, pp. 99-118.

LUIS CORRAL, Fernando - "Feudalismo y molinos: la posesión de aceñas en Zamora en el siglo XII". Studia Zamorensia 3 (1996), pp. 53-75.

MARTÍNEZ GIJÓN, José - “La práctica del fletamiento de mercancías con las Indias (siglo XVI)”. Historia. Instituciones. Documentos 10 (1983), pp. 119-156.

MONTANER SALAS, María Elena - “Aceñas y molinos de arcabuces en el paisaje del Campo de Cartagena". Revista murciana de antropología 10 (2004), pp. 121-128.

MONTES ROMERO-CAMACHO, Isabel - El paisaje rural sevillano en la Baja Edad Media. Sevilla: Diputación de Sevilla, 1989.

ORTIZ GARCÍA, José - "Las instalaciones hidráulicas montoreñas: las aceñas y batanes de Fernando Alonso entre la Edad Media y la Época Moderna”. Crónica de Córdoba y sus pueblos 14 (2008), pp. 103-114. 
PÉREZ MORENO, José Luis - "El reparto de los molinos en el siglo XIII: el caso de Alcalá de Guadaíra y Sevilla”. in GONZÁLEZ JIMÉNEZ, Manuel (Coord.) - Sevilla 1248. Congreso Internacional conmemorativo de la conquista de la ciudad de Sevilla por Fernando III, rey de Castilla y León. Sevilla: Centro de Estudios Ramón Areces, 2000, pp. 847-854.

PÉREZ-PRENDES MUÑOZ-ARRACO, José Manuel - “'General renunciación non vala'. Sobre doctrina y práctica en tiempos del 'ius commune"'. Glossae. Revista de Historia del Derecho Europeo 5-6 (1993-1994), pp. 75-114.

REVILLA CALVO, Víctor et al. - "Arva: prospecciones en un centro productor de ánforas Dressel 20 (Alcolea del Río, Sevilla)". Pyrenae: revista de prehistòria i antiguitat de la Meditirrànea Occidental 28 (1997), pp. 151-178.

RODRÍGUEZ BLANCO, Daniel - “El monasterio de Santiago de la Espada de Sevilla”. Historia. Instituciones. Documentos 6 (1979), pp. 309-324.

ROLDÁN CAÑAS, José - “Molinos, norias y batanes en la Península Ibérica durante la Edad Media". Boletín de la Real Academia de Córdoba 165 (2016), pp. 37-61.

ROLDÁN CAÑAS, JOsé - ; MORENO PÉREZ, María Fátima - "Water engineering and management in alAndalus". in CABRERA, Enrique; ARREGUI, Francisco (Eds.) - Water engineering and management through time - Learning from History. Londres: CRC Press, 2010, pp. 117-130.

SÁNCHEZ JIMÉNEZ, Francisco Javier - Estudio histórico-técnico de los molinos hidráulicos de Alcalá de Guadaíra. Sevilla: Universidad de Sevilla, 2015. Tesis Doctoral. Disponible en: https://idus.us.es/ xmlui/handle/11441/32058 [Último acceso: 1 de enero de 2018].

SANCHO CORBACHO, Antonio: “Haciendas y cortijos sevillanos”. Archivo Hispalense 54-56 (1952), pp. 2-26.

TORRES DELGADO, Cristóbal - Molinos y aceñas de la ciudad de Córdoba. Córdoba: Diputación de Córdoba, 2007.

TRUJILLO CLAVIJO, Celia - "Una encomienda de la Orden de San Juan”. in VV. AA. - Alcolea del Río. Historia de una población del Guadalquivir desde sus orígenes hasta el siglo XIX. Sevilla: Caja Rural de Sevilla, 1995, pp. 143-241.

URÍAS MARTÍNEZ, Rafael - "De las primeras evidencias hasta el fin de la Edad Antigua". in VV. AA. - Alcolea del Río. Historia de una población del Guadalquivir desde sus orígenes hasta el siglo XIX. Sevilla: Caja Rural de Sevilla, 1995, pp. 5-141.

\section{NOTAS}

1. LUIS CORRAL, Fernando - "Feudalismo y molinos: la posesión de aceñas en Zamora en el siglo XII". Studia Zamorensia 3 (1996), pp. 53-75, p. 53.

2. ROLDÁN CAÑAS, José - "Molinos, norias y batanes en la Península Ibérica durante la Edad Media". Boletín de la Real Academia de Córdoba 165 (2016), pp. 37-61; CARO BAROJA, Julio - Norias, azudas, aceñas. Madrid: CSIC, 1954; MONTANER SALAS, María Elena “Aceñas y molinos de arcabuces en el paisaje del Campo de Cartagena". Revista murciana de antropología 10 (2004), pp. 121-128; GONZÁLEZ TASCÓN, Ignacio - "La difusión medieval del molino hidráulico". in GRAU FERNÁNDEZ, Marta (Coord.) - Ars mechanicae: ingeniería medieval en España. Madrid: Ministerio de Fomento, 2008, pp. 99-118; ROLDÁN CAÑAS, José; MORENO PÉREZ, María Fátima - "Water engineering and management in al-Andalus". in 
CABRERA, Enrique; ARREGUI, Francisco (Eds.) - Water engineering and management through time - Learning from History. London: CRC Press, Taylor \& Francis, 2010, pp. 117-130.

3. Del árabe assánya, sinónimo de "elevadora".

4. LUIS CORRAL, Fernando - "Feudalismo y molinos", p. 54; ROLDÁN CAÑAS, José - "Molinos, norias y batanes", pp. 43-44; CÓRDOBA DE LA LLAVE, Ricardo - "Los molinos hidráulicos de la cuenca del Guadalquivir a fines de la Edad Media: instrumental y equipamiento técnico". Anuario de Estudios Medievales 33 (1) (2003), pp. 294-295.

5. LUIS CORRAL, Fernando - "Feudalismo y molinos", pp. 57 y 71.

6. CÓRDOBA DE LA LLAVE, Ricardo - “Los molinos hidráulicos de la cuenca del Guadalquivir”, pp. 291-337.

7. TORRES DELGADO, Cristóbal - Molinos y aceñas de la ciudad de Córdoba. Córdoba: Diputación de Córdoba, 2007; CÓRDOBA DE LA LLAVE, Ricardo - “Aceñas, tahonas y almazaras: técnicas industriales y procesos productivos del sector agroalimentario en la Córdoba del siglo XV". Hispania 48 (170) (1988), pp. 827-874; CÓRDOBA DE LA LLAVE, Ricardo - "El molino de Martos (Córdoba): de la aceña medieval a la adopción del sistema de regolfo (siglos XV-XVI)". in Actas del IV Congreso Internacional de Molinología. Mallorca: Consejo Insular de Mallorca, 2005, vol. I, pp. 207-228; CÓRDOBA DE LA LLAVE, Ricardo - "El proceso de difusión del molino de regolfo y la sustitución de aceñas de origen medieval en la provincia de Córdoba". Arte, arqueología e historia 17 (2010), pp. 249-264; CÓRDOBA DE LA LLAVE, Ricardo - Los molinos hidráulicos del Guadalquivir en la ciudad de Córdoba. Estudio histórico y arquitectónico. Madrid: Ministerio de Fomento, 2008; CÓRDOBA DE LA LLAVE, Ricardo et al. - Puertos, azudes y norias. El patrimonio hidráulico histórico de Palma del Río (Córdoba). Sevilla: Fundación El Monte, 2004; ORTIZ GARCÍA, José - "Las instalaciones hidráulicas montoreñas: las aceñas y batanes de Fernando Alonso entre la Edad Media y la Época Moderna". Crónica de Córdoba y sus pueblos 14 (2008), pp. 103-114.

8. SÁNCHEZ JIMÉNEZ, Francisco Javier - Estudio histórico-técnico de los molinos hidráulicos de Alcalá de Guadaíra. Sevilla: Universidad de Sevilla, 2015. Tesis Doctoral. Disponible en: https:// idus.us.es/xmlui/handle/11441/32058 [Último acceso: 1 de enero de 2018]; PÉREZ MORENO, José Luis - "El reparto de los molinos en el siglo XIII: el caso de Alcalá de Guadaíra y Sevilla". in GONZÁLEZ JIMÉNEZ, Manuel (Coord.) - Sevilla 1248. Congreso Internacional conmemorativo de la conquista de la ciudad de Sevilla por Fernando III, rey de Castilla y León. Sevilla: Centro de Estudios Ramón Areces, 2000, pp. 847-854.

9. Aunque, como sucedía en Carmona, debido a que la mayor parte de los terrenos eran propiedad de personas ajenas al municipio, la propia población de la zona sufría problemas de abastecimiento. Véase GONZÁLEZ JIMÉNEZ, Manuel - El concejo de Carmona a fines de la Edad Media (1464-1523). Sevilla: Diputación de Sevilla, 1973, pp. 251-253.

10. MONTES ROMERO-CAMACHO, Isabel - El paisaje rural sevillano en la Baja Edad Media. Sevilla: Diputación de Sevilla, 1989, p. 479.

11. MONTES ROMERO-CAMACHO, Isabel - El paisaje rural sevillano, pp. 479-484.

12. GONZÁLEZ CARBALLO, José - Formación y consolidación del señorío de la Orden de San Juan en Andalucía: siglos XIII-XVI. Sevilla: Diputación de Sevilla, 2004, p. 94.

13. Este último por donación de la reina doña Juana de Ponthieu, segunda esposa de Fernando III, en el año 1250: Libro de privilegios de la Orden de San Juan de Jerusalén en Castilla y León (siglos XII-XV) - Museum and Library of the Order of Saint John (MLOSJ), ms. H211. Ed. Carlos de Ayala Martínez et al. Madrid: Editorial Complutense, 1995, p. 519, doc. 309; GONZÁLEZ CARBALLO, José - Formación y consolidación, p. 92.

14. Este interés de los cabildos catedralicios y las órdenes militares en la posesión de aceñas y molinos también se dio en otras zonas de la Península como el Duero: LUIS CORRAL, Fernando "Feudalismo y molinos", pp. 61 y 66-67.

15. BORRERO FERNÁNDEZ, Mercedes - "Cambios políticos y paisaje agrario en la Edad Media. El ejemplo del campo andaluz (s. XIII-XV)”. Cuadernos del CEMYR 7 (1999), pp. 69-94, p. 90. 
16. BORRERO FERNÁNDEZ, Mercedes - El mundo rural sevillano en el siglo XV: Aljarafe y Ribera. Sevilla: Diputación de Sevilla, 1983, pp. 87-88.

17. BORRERO FERNÁNDEZ, Mercedes - El mundo rural sevillano", p. 241.

18. MONTES ROMERO-CAMACHO, Isabel - El paisaje rural sevillano p. 195.

19. Sobre su presencia en la Península, pueden verse las siguientes referencias: AYALA MARTÍNEZ, Carlos de - "Orígenes de la Orden del Hospital en Castilla y León (1113-1157)". Hispania Sacra 43 (1991), pp. 775-798; AYALA MARTÍNEZ, Carlos de - "Orígenes e implantación de la Orden de Jerusalén en la Península Ibérica (siglo XII)”. in IZQUIERDO BENITO, Ricardo et al. (Coords.) - La Orden Militar de San Juan en la Península Ibérica durante la Edad Media. Alcázar de San Juan: Patronato Municipal de Cultura de Alcázar de San Juan, 2002, pp. 23-41; BARQUERO GOÑI, Carlos - Los Hospitalarios en Castilla y León (siglos XII y XIII): señoríos de la Orden de San Juan. Madrid: Universidad Autónoma de Madrid, 1995; BARQUERO GOÑI, Carlos - "La Orden de San Juan en Castilla y León durante la Edad Media (siglos XII-XV)". in IZQUIERDO BENITO, Ricardo et al. (Coords.) - La Orden Militar de San Juan, pp. 97-120.

20. GONZÁLEZ CARBALLO, José - Formación y consolidación, pp. 67-100.

21. Para todo este apartado seguimos a TRUJILLO CLAVIJO, Celia - "Una encomienda de la Orden de San Juan". in VV. AA - Alcolea del Río. Historia de una población del Guadalquivir desde sus orígenes hasta el siglo XIX. Sevilla: Caja Rural de Sevilla, 1995, pp. 145-176 y GONZÁLEZ CARBALLO, José - La Orden de San Juan en Andalucía (siglos XIII-XVI). Las Encomiendas. Sevilla: Fundación El Monte, 2002, pp. 105-159; GONZÁLEZ CARBALLO, José - Formación y consolidación, pp. 136-144; GONZÁLEZ CARBALLO, José - "La división de la cámara prioral de Lora y su separación del Priorato: la creación de la encomienda de Alcolea y el bailiaje de Lora". Archivo Hispalense 261-266 (2003-2004), pp. 155-166.

22. Se conserva el privilegio de donación, fechado el 15 de enero de 1249: MLOSJ, ms. H211, ff. 30-31r., Libro de privilegios de la Orden de San Juan de Jerusalén, pp. 517-518, doc. 308.

23. URÍAS MARTÍNEZ, Rafael - "De las primeras evidencias hasta el fin de la Edad Antigua". in VV. AA. - Alcolea del Río. Historia de una población, pp. 13-17 y 63-141.

24. GÓMEZ DE TERREROS GUARDIOLA, Ma Gracia - "La arquitectura de la Orden de San Juan de Jerusalén en la provincia de Sevilla". in GÓMEZ DE TERREROS GUARDIOLA, M ${ }^{a}$ Valle (Coord.) - La arquitectura de las órdenes militares en Andalucía: conservación y restauración. Huelva: Universidad de Huelva, 2011, p. 107; CARO QUESADA, Ma Josefa Salud - “Alcolea del Río”. in MORALES PADRÓN, Francisco (Coord.) - Catálogo de los archivos parroquiales de la provincia de Sevilla. Sevilla: Banco Español de Crédito, 1992, tomo I, pp. 41-45.

25. MLOSJ, ms. H211, ff. 367-372r., Libro de privilegios de la Orden de San Juan de Jerusalén, pp. 667-669 y 676-682, docs. 418, 421, 423 y 424; GONZÁLEZ CARBALLO, José - Formación y consolidación ,pp. 140-141.

26. TRUJILlO CLAVIJO, Celia - "Una encomienda de la Orden de San Juan", p. 211.

27. En algunos casos sabemos que el grupo estaba compuesto por varios molinos. En otros la realidad es algo ambigua porque la documentación se refiere a ellas tanto en plural como en singular.

28. Sobre este alcaide sabemos que edificó además otras aceñas en el término de Carmona, que vendió en 1416 a Juan de las Casas, veinticuatro de Sevilla. Véase GONZÁLEZ JIMÉNEZ, Manuel Catálogo de documentación medieval del Archivo Municipal de Carmona, vol. I (1249-1474). Sevilla: Diputación de Sevilla, 1976, p. 57, n 185. Cit. por GONZÁLEZ CARBALLO, José - Formación y consolidación, p. 142.

29. MLOSJ, ms. H211, ff. 359v-365r., Libro de privilegios de la Orden de San Juan de Jerusalén, pp. 692-696, doc. 430.

30. MLOSJ, ms. H211, ff. 359v-365r., Libro de privilegios de la Orden de San Juan de Jerusalén, pp. 692-696, doc. 430 . 
31. MLOSJ, ms. H211, ff. 359v-367r., Libro de privilegios de la Orden de San Juan de Jerusalén, pp. 697-700, doc. 432.

32. GONZÁLEZ CARBALLO, José - La Orden de San Juan en Andalucía, p. 109.

33. TRUJILLO CLAVIJO, Celia - "Una encomienda de la Orden de San Juan", p. 194.

34. Archivo Histórico de la Nobleza (AHN), Osuna, c. 137, docs. 62-63.

35. TRUJILLO CLAVIJO, Celia - "Una encomienda de la Orden de San Juan", p. 194.

36. GONZÁLEZ JIMÉNEZ, Manuel - El concejo de Carmona, p. 201, nota 67. Cit. por TRUJILLO CLAVIJO, Celia - "Una encomienda de la Orden de San Juan”, p. 194 y GONZÁLEZ CARBALLO, José - Formación y consolidación, p. 142.

37. GÓMEZ DE TERREROS GUARDIOLA, Ma Gracia - "La arquitectura de la Orden de San Juan”, p. 108; ALBERRO SÁNCHEZ, Rafael - "Las aceñas de Alcolea del Río”. Aparejadores: boletín del Colegio Oficial de Aparejadores y Arquitectos Técnicos de Sevilla 49 (1997), pp. 88-95; SANCHO CORBACHO, Antonio - "Haciendas y cortijos sevillanos". Archivo Hispalense 54-56 (1952), pp. 2-26; ANGULO ÍÑIGUEZ, Diego - Arquitectura mudéjar sevillana de los siglos XIII, XIV y XV. Sevilla: Universidad de Sevilla, 1932, p. 13.

38. Se trata en realidad de dos molinos harineros y un batán, los primeros con ruedas horizontales y el batán con rueda vertical.

39. GÓMEZ DE TERREROS GUARDIOLA, Mª Gracia - "La arquitectura de la Orden de San Juan", p. 108.

40. SANCHO CORBACHO, Antonio: "Haciendas y cortijos", p. 26.

41. URÍAS MARTÍNEZ, Rafael - "De las primeras evidencias”, pp. 63-141; REVILLA CALVO, Víctor et al. - "Arva: prospecciones en un centro productor de ánforas Dressel 20 (Alcolea del Río, Sevilla)". Pyrenae: revista de prehistòria i antiguitat de la Meditirrànea Occidental 28 (1997), pp. 151-178.

42. URÍAS MARTÍNEZ, Rafael - "De las primeras evidencias", pp. 13-14.

43. GONZÁLEZ CARBALLO, José - La Orden de San Juan en Andalucía, p. 143.

44. GONZÁLEZ CARBALLO, José - La Orden de San Juan en Andalucía, pp. 135-145; TRUJILlO CLAVIJO, Celia - "Una encomienda de la Orden de San Juan”, pp. 163-164.

45. LUIS CORRAL, Fernando - "Feudalismo y molinos", p. 71.

46. El documento está otorgado ante notario el 2 de agosto de 1405 en Villanueva del Camino, localidad contigua a Alcolea: MLOSJ, ms. H211, ff. 359v-365r., Libro de privilegios de la Orden de San Juan de Jerusalén, pp. 689-696, docs. 429 y 430.

47. LUIS CORRAL, Fernando - "Feudalismo y molinos", p. 70.

48. Los del río eran barbos, bogas, anguilas y lampreas. Los que subían del mar: sábalos, sollos, albures y sabogas. Véase GONZÁLEZ CARBALLO, José - Formación y consolidación, p. 142.

49. A mediados del siglo XVI estas condiciones habían cambiado, debiendo el duque de Arcos, propietario en esa fecha, entregar anualmente a la Orden ocho cahíces de trigo en especie y mil maravedíes en metálico; y a finales de la misma centuria las cantidades ascendían a 90 fanegas de trigo y mil maravedíes. Véase GONZÁLEZ CARBALLO, José - Formación y consolidación, pp. 142-143. 50. PÉREZ-PRENDES MUÑOZ-ARRACO, José Manuel - “'General renunciación non vala'. Sobre doctrina y práctica en tiempos del 'ius commune"'. Glossae. Revista de Historia del Derecho Europeo 5-6 (1993-1994), p. 76.

51. PÉREZ-PRENDES MUÑOZ-ARRACO, José Manuel - “'General renunciación”, p. 78.

52. PÉREZ-PRENDES MUÑOZ-ARRACO, José Manuel - “'General renunciación”, p. 80.

53. PÉREZ-PRENDES MUÑOZ-ARRACO, José Manuel - “General renunciación”, p. 79.

54. MARTÍNEZ GIJÓN, José - "La práctica del fletamiento de mercancías con las Indias (siglo XVI)”. Historia. Instituciones. Documentos 10 (1983), p. 140.

55. PÉREZ-PRENDES MUÑOZ-ARRACO, José Manuel - “'General renunciación”, pp. 95-101.

56. GONZÁLEZ CARBALLO, José - La Orden de San Juan en Andalucía, p. 143. 
57. MLOSJ, ms. H211, ff. 359-367r., Libro de privilegios de la Orden de San Juan de Jerusalén, pp. 696-700, docs. 431 y 432; GONZÁLEZ CARBALLO, José - La Orden de San Juan en Andalucía, p. 110.

58. RODRÍGUEZ BLANCO, Daniel - "El monasterio de Santiago de la Espada de Sevilla". Historia. Instituciones. Documentos 6 (1979), pp. 309-324.

59. GONZÁLEZ CARBALLO, José - "La Orden de San Juan en Sevilla (siglos XIII-XVI)". Historia. Instituciones. Documentos 29 (2002), pp. 163-186.

60. AHN, Osuna, C. 137 , doc. 84.

61. AHN, Osuna, C. 137, doc. 85.

62. LUIS CORRAL, Fernando - "Feudalismo y molinos", p. 74.

\section{RESUMOS}

En el presente trabajo centramos nuestra atención en el estudio de una encomienda de la Orden de San Juan en la Andalucía de la Baja Edad Media: Alcolea del Río, en la actual provincia de Sevilla. Alcolea, por su proximidad al río Guadalquivir, supo utilizar este recurso como una herramienta para potenciar su crecimiento económico mediante la construcción y explotación de distintos grupos de aceñas, que estudiamos detalladamente en este trabajo. El crecimiento demográfico y económico experimentado por la población durante el siglo XV le permitió alcanzar la categoría de encomienda independiente de la de Lora del Río en 1504.

In this paper we focus our attention on the study of a territory governed by the Order of Saint John in Andalusia at the end of the Middle Ages: Alcolea del Río, in the province of Seville (Spain). This town, due to its proximity to Guadalquivir river, was able to take advantage of this resource in order to improve its economic and demographic development, by constructing and using different groups of water mills. We study them in this paper. The development experienced by Alcolea during the 15th century was the cause of an important achievement at the beginning of the Early Modern period: its independence from Lora del Río in 1504.

\section{ÍNDICE}

Keywords: Andalusia, military orders, Order of Saint John, water mills, Guadalquivir river.

Palabras claves: Andalucía, órdenes militares, Orden de San Juan, aceñas, río Guadalquivir.

\section{AUTOR}

\section{JUAN CARLOS ARBOLEDA GOLDARACENA}

Universidad Pablo de Olavide de Sevilla, Facultad de Humanidades; Área de Historia Medieval; Departamento de Geografía, Historia y Filosofía, 41013, Sevilla, España

jcarbgol@upo.es 